\title{
Identificação e validação de marcadores microssatélites ligados ao gene Rpp5 de resistência à ferrugem-asiática-da-soja
}

\author{
Thaiza Galhardo Silva Morceli(1), Sandra Helena Unêda Trevisoli(2), Antonio Ayrton Morceli Junior(1), \\ Romeu Afonso de Souza Kiihl(2), Eberson Sanches Calvo ${ }^{(2)}$, Antonio Orlando Di Mauro(1) e Alexandre Garcia(3) \\ (1)Universidade Estadual Paulista, Faculdade de Ciências Agrárias e Veterinárias, Campus de Jaboticabal, Departamento de Produção \\ Vegetal, Via de Acesso Prof. Paulo Donato Castellane, s/no, CEP 14884-900 Jaboticabal, SP. E-mail: thagalhardo@hotmail.com, \\ morceli@fcav.unesp.br, orlando@fcav.unesp.br (2)Faculdade de Tecnologia de Jaboticabal, Via de Acesso Prof. Paulo Donato Castellane, \\ s/no, CEP 14884-900 Jaboticabal, SP. E-mail: sahuneda@hotmail.com ${ }^{(3)}$ Tropical Melhoramento e Genética Ltda., Rodovia Celso Garcia Cid, \\ Km 87, CEP 86183-600 Cambé, PR. E-mail: romeu@tmg.agr.br, ebersoncalvo@tmg.agr.br, le_garcia09@hotmail.com
}

Resumo - O objetivo deste trabalho foi identificar novos marcadores microssatélites, ligados ao gene Rpp 5 de resistência à ferrugem-da-soja, e validar os marcadores previamente mapeados, para que possam ser utilizados em programas de seleção assistida por marcadores moleculares (SAM). Para tanto, uma população $F_{2}$ com 100 indivíduos, derivada do cruzamento entre a PI 200526 e a cultivar Coodetec 208, suscetível à ferrugem, foi artificialmente infectada e avaliada quanto à sua reação de resistência à ferrugem. Marcadores microssatélites foram testados nos genitores e em dois "bulks" contrastantes, para a identificação de marcadores ligados. Dois novos marcadores, potencialmente associados à resistência, foram testados em plantas individuais, e se constatou que eles estão ligados ao gene Rpp5 e estão presentes no grupo de ligação $\mathrm{N}$ da soja. A eficiência de seleção foi determinada em relação a todos os marcadores ligados ao gene $R p p 5$, e a combinação entre os marcadores Sat_275+Sat_280 foi de 100\%.

Termos para indexação: Glycine max, Phakopsora pachyrhizi, seleção assistida por marcadores, SSR.

\section{Identification and validation of microsatellite markers linked to the Rpp5 gene conferring resistance to Asian soybean rust}

\begin{abstract}
The main objective of this work was to identify new microsatellite markers, linked to the Rpp5 resistance gene to Asian soybean rust, and to validate previously mapped markers for use in marker-assisted selection (MAS) programs. To this end, a $F_{2}$ population with 100 individuals, derived from crossing between PI 200526 and cultivar Coodetec 208, susceptible to rust, was artificially infected and evaluated for its reaction of resistance to rust. Microsatellite markers were tested on parents and in the two contrasting bulks to identifying linked markers. Two new markers, potentially associated with resistance, were tested in individual plants, and they were found to be linked to gene Rpp5 and to be present in the $\mathrm{N}$ linkage group of soybean. The selection efficiencies were determined for all markers linked to gene Rpp5, and the combination of the markers Sat_275+Sat_280 was 100\%.
\end{abstract}

Index terms: Glycine max, Phakopsora pachyrhizi, marker assisted selection, SSR.

\section{Introdução}

A soja é uma espécie originária da Ásia, e vem sendo cultivada há centenas de anos; em razão de suas características nutritivas e industriais e de sua adaptabilidade a diferentes latitudes, solos e condições climáticas, o cultivo se expandiu por todo o mundo, constituindo-a em uma das principais leguminosas atualmente (Martins, 2006).

A produção mundial de soja, prevista para o ano agrícola 2007/2008, é de cerca de 221,3 milhões de toneladas, das quais os Estados Unidos devem produzir 71,2 milhões de toneladas, segundo o relatório do
Departamento de Agricultura dos Estados Unidos (Usda), mantendo-se como o maior produtor mundial, seguido do Brasil com produção em torno de 59,6 milhões de toneladas (Conab, 2008).

Embora o Brasil tenha aumentado sua produção e produtividade, nos últimos anos, a cultura apresenta um potencial ainda maior e, entre os fatores que impedem que seu potencial máximo seja atingido estão as doenças (Alves, 2007). Aproximadamente 50 doenças já foram identificadas no Brasil, e este número continua aumentando, em razão da expansão da fronteiras agrícolas e da prática da monocultura.

Pesq. agropec. bras., Brasília, v.43, n.11, p.1525-1531, nov. 2008 
A doença que mais preocupa os sojicultores, atualmente, é a ferrugem-asiática, causada pelo fungo Phakopsora pachyrhizi que, desde a sua primeira ocorrência, foi responsável por severos danos econômicos, tendo causado perdas de rendimento de até $70 \%$ (Soares et al., 2004).

As reações associadas à doença se manifestam como lesões formadas nas folhas, que podem ser classificadas como do tipo castanho-claras (TAN), características de plantas suscetíveis, e do tipo castanho-avermelhadas (RB - "reddish brown"), típicas de plantas resistentes (Zambenedetti et al., 2007).

O uso de fungicidas é o método mais empregado para o controle da doença, porém sua aplicação deve ser feita de forma racional, para não inviabilizar a cultura e agredir o meio ambiente de forma indiscriminada (Godoy \& Canteri, 2004). Assim, o uso de cultivares resistentes é o método mais indicado para o controle da doença.

Estão referenciados até o momento, na literatura, cinco genes de resistência independentes: Rpp 1 (PI 200692), Rpp2 (PI 230970), Rpp3 (PI 462312) e Rpp4 (PI 459025) (Bromfield \& Hartwig, 1980; Mclean \& Byth, 1980; Hartwig \& Bromfield, 1983; Hartwig, 1986) e Rpp5, recentemente mapeado no grupo de ligação N da soja (Garcia et al., 2008).

Até o presente momento, não está disponível no mercado nenhuma cultivar que seja portadora de qualquer gene de resistência a esse patógeno.

As cultivares comerciais, geralmente, são desenvolvidas por transferência de alelos de resistência, oriundas de fontes exóticas e, muitas vezes, não adaptadas, para cultivares elite. No processo de transferência de genes de resistência, os marcadores moleculares podem ser uma ferramenta bastante útil. Esses marcadores, se estreitamente ligados aos genes de resistência, podem ser usados na seleção assistida por marcadores (SAM), particularmente nas etapas iniciais e intermediárias do melhoramento (Alzate-Marin, 2005).

A busca por novas fontes de resistência e a identificação de novos marcadores ligados a locos já mapeados deverão ser contínuas, e o monitoramento desses genes será fundamental para o desenvolvimento de cultivares com resistência satisfatória.

O objetivo deste trabalho foi identificar novos marcadores microssatélites, ligados ao gene Rpp 5 de resistência à ferrugem-da-soja, presente na linhagem
PI 200526, além de validar esses novos marcadores e os previamente identificados como associados à resistência a essa doença, a fim de verificar sua eficiência de seleção (ES) para que possam ser utilizados em programas de seleção assistida por marcadores moleculares (SAM).

\section{Material e Métodos}

As etapas experimentais foram realizadas no Laboratório de Biotecnologia Aplicada ao Melhoramento de Plantas, do Departamento de Produção Vegetal da Faculdade de Ciências Agrárias e Veterinárias da Unesp, Campus de Jaboticabal, e na Empresa Tropical Melhoramento e Genética (TMG), em Cambé, PR.

Uma população $\mathrm{F}_{2}$ com 100 indivíduos, derivada do cruzamento entre a linhagem PI 200526, resistente à ferrugem-asiática, na qual o gene Rpp 5 foi identificado, e a cultivar brasileira Coodetec 208, suscetível ao patógeno, foi utilizada para caracterização fenotípica, quanto à reação de resistência e suscetibilidade ao fungo Phakopsora pachyrhizi e à identificação de marcadores microssatélites ligados ao gene Rpp5.

A população de mapeamento e os genitores foram cultivados em casa de vegetação, em vasos de sete litros com solo devidamente preparado. Em cada vaso, foram cultivadas três plantas $F_{2}$, que foram devidamente identificadas com um número para a avaliação da reação à ferrugem-asiática e para a coleta de folhas para as análises moleculares.

Para a avaliação fenotípica da reação à ferrugem, foram realizadas inoculações a partir de uma mistura de isolados da doença. O inóculo foi preparado a partir de folhas infectadas, que foram lavadas em solução água destilada + Tween 20 ( 1 gota para cada $100 \mathrm{~mL}$ de água), para a retirada dos esporos da superfície abaxial. As plantas $F_{2}$ foram pulverizadas com suspensão calibrada para $10^{4}$ uredósporos $\mathrm{mL}^{-1}$. A primeira inoculação foi realizada, quando a planta atingiu o estádio V2 da escala de Fehr \& Caviness (1977), tendo sido feitas posteriormente mais sete inoculações, em um intervalo de quatro dias.

Após o aparecimento dos sintomas, plantas resistentes e suscetíveis foram discriminadas pelas reações típicas de cada situação. Lesões RB são características de genótipos resistentes, e lesões TAN caracterizam os genótipos suscetíveis. Essa avaliação qualitativa classificou cada uma das 100 plantas $F_{2}$ em 
resistentes ou suscetíveis, de acordo com a reação do genótipo à presença da doença.

Os dados da avaliação fenotípica foram submetidos ao teste de aderência ao modelo de um gene dominante, pelo teste do qui-quadrado ( $>0,05)$.

Trifólios dos genótipos parentais e dos 100 indivíduos da população segregante foram coletados, liofilizados e submetidos à extração de DNA, pelo método CTAB (brometo de cetiltrimetilamônio), conforme descrito por Ferreira \& Grattapaglia (1998).

O DNA extraído foi quantificado, mediante leitura da densidade ótica a 260 e $280 \mathrm{~nm}$ em aparelho BioPhotometer Eppendorf AG. Posteriormente à quantificação, a integridade do DNA foi observada pela visualização em gel de agarose $0,8 \%$, corado com brometo de etídeo. Por fim, alíquotas das amostras de DNA foram diluídas à concentração de $30 \mathrm{ng} \mu \mathrm{L}^{-1}$, para serem utilizadas como solução de trabalho, e parte foi estocada a $-20^{\circ} \mathrm{C}$, para uso posterior.

De acordo com os resultados da avaliação fenotípica, quantidades equimolares de DNA, de 10 indivíduos resistentes e 10 suscetíveis, foram utilizados para a montagem dos "bulks" contrastantes, conforme a metodologia BSA ("bulked segregant analysis") desenvolvida por Michelmore et al. (1991). As amostras de DNA dos genitores e dos dois "bulks" foram utilizadas para os testes de marcadores microssatélites (SSR).

Para facilitar a identificação de marcadores, ligados ao gene de resistência à ferrugem-asiática, presente na linhagem PI 200526, foram utilizados neste trabalho, primeiramente, marcadores conhecidos por sua ligação a locos de resistência a doenças da soja. Estratégia similar também foi utilizada para mapear outros locos de resistência na soja (Mian et al., 1999; Gordon et al., 2006; Silva et al., 2008). Assim, foram testados 50 marcadores microssatélites, para verificar o polimorfismo entre os genitores, dos quais nove se apresentaram polimórficos e foram utilizados na discriminação dos "bulks" contrastantes.

A informação de seqüência dos iniciadores, para todos os marcadores SSR utilizados, foi encontrada no site Soybase (http://soybase.agron.iastate.edu/ resources/ssr.php).

As reações de amplificação foram realizadas com o volume total de $20 \mu \mathrm{L}$, tendo-se utilizado, $300 \mathrm{ng}$ de DNA genômico de soja, $1,5 \mathrm{mM}$ de $\mathrm{MgCl}_{2}$, tampão PCR 1X (10 mM Tris- $\mathrm{HCl}, \mathrm{pH} 8$ e $50 \mathrm{mM} \mathrm{KCl})$,
0,2 $\mathrm{mM}$ de dNTP, $1 \mathrm{U}$ de Taq-DNA polimerase e $10 \mu \mathrm{M}$ de cada iniciador Forward e Reverse.

O programa utilizado para a amplificação do DNA consistiu de $7 \min$ a $94^{\circ} \mathrm{C}, 30$ ciclos de $1 \min$ a $94^{\circ} \mathrm{C}$, $1 \min$ a $55^{\circ} \mathrm{C}, 2 \min$ a $72^{\circ} \mathrm{C}$, seguidos por $7 \min$ a $72^{\circ} \mathrm{C}$.

Os produtos amplificados foram separados por eletroforese, em gel de agarose de alta resolução (agarose 1000), à concentração de 3\% para melhor padrão de diferenciação de bandas, em tampão TAE (2 M Tris, 100 mM EDTA, 1 Mácido acético), e corados com brometo de etídeo. Procedeu-se à eletroforese a $80 \mathrm{~V}$, por cerca de 2 horas. A visualização foi feita em luz UV, por meio de transluminador, e fotografada pelo sistema Kodak EDAS 290. O tamanho de cada marca foi estimado por meio de comparação com o marcador de tamanho $100 \mathrm{pb}$ e, também, pelas ferramentas digitais do programa Kodak EDAS 290.

Os marcadores amplificados, em todos os indivíduos $\mathrm{F}_{2}$, foram submetidos ao teste de aderência ao modelo de um gene dominante, pelo teste do qui-quadrado, a 5\% de probabilidade. A análise de ligação e a construção do mapa foram realizadas com o auxílio do programa GQMOL 9.1 (Cruz \& Schuster, 2006), com a função de mapeamento de Kosambi (Kosambi, 1944). O critério de ligação foi um LOD escore maior que 3 e a distância máxima de $37,2 \mathrm{cM}$.

A eficiência de seleção (ES) dos marcadores, identificados no presente estudo, e dos marcadores previamente identificados por Garcia et al. (2008) como ligados ao gene Rpp 5 de resistência à ferrugemasiática-da-soja, foi calculada de acordo com Silva et al. (2007), pela fórmula:

$\mathrm{SE}=100[(\mathrm{MFMF}+\mathrm{mfmf}) /(\mathrm{MM}+\mathrm{mm})$,

em que: MFMF é o número de plantas selecionadas, corretamente, como resistentes, com base nos marcadores e na avaliação fenotípica; mfmf, o número de plantas selecionadas, corretamente, como suscetíveis, com base nos marcadores e na avaliação fenotípica; $\mathrm{MM}$ e $\mathrm{mm}$, número total de plantas resistentes e suscetíveis, respectivamente, com base apenas nos marcadores.

\section{Resultados e Discussão}

Após a inoculação do patógeno, as reações genéticas à ferrugem-asiática foram avaliadas nos genitores (linhagem PI 200526 e cultivar Coodetec 208), assim como nos 100 indivíduos da progênie $F_{2}$ derivada desse cruzamento. 
Todas as plantas da cultivar suscetível apresentaram lesões TAN, em plena esporulação, enquanto a linhagem PI 200526 apresentou somente lesões do tipo RB, característica de genótipos resistentes.

Das 100 progênies $F_{2}, 82$ foram caracterizadas como resistentes e 18 suscetíveis. A proporção observada foi testada para verificar a conformidade com a proporção mendeliana esperada de $3: 1$. $\mathrm{Na}$ Tabela 1, pode ser observado o valor qui-quadrado 2,61, que confirma, satisfatoriamente, a segregação esperada para um único gene ( $R p p 5)$ com dominância completa. Resultados semelhantes foram encontrados por Garcia et al. (2007), que mapearam o gene $R p p 5$, em três genótipos exóticos. Dois outros genes de ação dominante ( $R p p 2$ e $R p p 4)$, que condicionam resistência à ferrugem-asiática, foram encontrados nas linhagens PI 230970 e PI 459025, respectivamente, por Silva et al. (2008). Hyten et al. (2007) encontraram na PI 200429, um gene dominante $(R p p l)$ condiciona resistência ao isolado de ferrugem India-73-1.

Dos cinqüenta marcadores SSR, testados nos genitores, nove comportaram-se como polimórficos e foram testados nos "bulks" contrastantes. Destes, apenas três (Satt009, Satt152, Sat_166) possibilitaram a diferenciação entre os "bulks" resistentes e suscetíveis, e foram amplificados em todos os indivíduos da população e testados quanto à adequação de segregação, em que se enquadraram satisfatoriamente à razão esperada para uma herança co-dominante (1:2:1), de acordo com a natureza do marcador, considerando-se a probabilidade de 5\% (Tabela 1).

Tabela 1. Teste de qui-quadrado $\left(\chi^{2}\right)$ da segregação fenotípica da população $\mathrm{F}_{2}$, de mapeamento do loco $\operatorname{Rpp} 5$, e dos marcadores microssatélites polimórficos ${ }^{(1)}$.

\begin{tabular}{|c|c|c|c|c|c|}
\hline Caráter & \multicolumn{2}{|c|}{ A } & $\mathrm{B}$ & Segregação & $\chi^{2}$ \\
\hline Avaliação fenotípica & \multicolumn{2}{|c|}{82} & 18 & $3: 1$ & $2,61^{\mathrm{ns}}$ \\
\hline Marcador & $\mathrm{R}$ & $\mathrm{H}$ & $\mathrm{S}$ & Segregação & \\
\hline Satt009 & 27 & 46 & 27 & $1: 2: 1$ & $0,64^{\mathrm{ns}}$ \\
\hline Satt152 & 29 & 45 & 26 & $1: 2: 1$ & $1,18^{\text {ns }}$ \\
\hline Sat_166 & 28 & 46 & 26 & $1: 2: 1$ & $0,72^{\text {ns }}$ \\
\hline Sat_275 & 27 & 50 & 23 & $1: 2: 1$ & $0,32^{\text {ns }}$ \\
\hline Sat_280 & 23 & 52 & 25 & $1: 2: 1$ & $0,24^{\mathrm{ns}}$ \\
\hline
\end{tabular}

${ }^{(1)} \mathrm{A}$, plantas que apresentaram lesões do tipo RB (resistentes); B, plantas que apresentaram lesões do tipo TAN (suscetíveis); R, homozigoto resistente; $\mathrm{H}$, heterozigoto; S, homozigoto suscetível. ${ }^{\text {ns }}$ Não-significativo a 5\% de probabilidade, pelo teste do qui-quadrado.
O teste qui-quadrado também foi utilizado para testar a hipótese de segregação independente de cada marcador com o gene de resistência. Os valores $\chi^{2}$ para os marcadores foram os seguintes: para Satt009, $31,27(\mathrm{p}<0,001)$; para Satt152, 32,55 $(\mathrm{p}<0,001)$; e, para Sat_166, 52,60 $(\mathrm{p}<0,001)$. Todos os valores de qui-quadrado foram altamente significativos, o que indica que a hipótese de segregação independente não foi aceita, podendo-se, portanto, concluir que esses marcadores SSR estão ligados ao loco de resistência $R p p 5$.

Com o auxílio do programa GQMOL 9.1 (Cruz \& Schuster, 2006), foram estimadas as distâncias entre cada marcador e o loco Rpp5, o desvio-padrão e os valores de LOD escore (Tabela 2).

O loco Rpp5 foi mapeado no grupo de ligação $\mathrm{N}$ da soja, o que corrobora os dados de Garcia et al. (2008), em distância estimada de 9,1 $\pm 29 \mathrm{cM}$ do marcador Sat 166. Os marcadores Satt009 e Satt152 foram posicionados em distância estimada

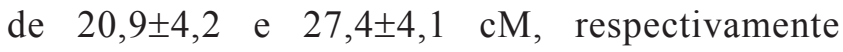
(Figura 1).

Garcia et al. (2008) mapearam o loco Rpp5, em três populações diferentes (PI 200456, PI 471904 e PI 200526), e obtiveram: seis marcadores ligados a este loco na população PI 200456 (Satt530, Sat_208, Sat_166, Sat_275, Sat_280 e Sat_266); e cinco na PI471904 (Satt530, Sat_208, Sat_166, Sat_275, Sat_280) e três na PI 200526 (Sat_166, Sat_275 e Sat_280). Esta última foi a mesma população mapeada no presente trabalho, porém com dois diferentes marcadores Satt009 e Satt152, além do Sat_166. Esses resultados se somam ao trabalho de Garcia et al. (2008), e a ordem dos marcadores microssatélites foi consistente, em ambos os trabalhos, com o mapa de ligação consenso da soja (Song et al., 2004).

Alguns locos de características quantitativas (QTL), importantes para resistência a algumas doenças da soja, foram mapeados na região

Tabela 2. Estimativa das distâncias entre cada marcador e o loco Rpp 5, desvio-padrão e valores de LOD escore gerados pelo programa GQMOL 9.1 (Cruz \& Schuster, 2006).

\begin{tabular}{lccc}
\hline Marcadores & Distância $(\mathrm{cM})$ & Desvio-padrão & LOD escore \\
\hline Satt009 & 20,9 & 4,21 & 6,11 \\
Satt152 & 27,4 & 4,11 & 6,64 \\
Sat_166 & 9,1 & 2,95 & 11,68 \\
\hline
\end{tabular}


cromossômica vizinha ao loco de resistência à ferrugem Rpp5. Próximos ao marcador Satt009, foram mapeados QTL de resistência ao patógeno Sclerotinia sclerotiorum, fungo causador do mofo-branco, na cultura da soja (Arahana, 2001) e, em uma região cromossômica adjacente, encontra-se mapeado um QTL de resistência ao nematóide-do-cisto, causador de uma das mais sérias ameaças a sojicultura (Concibido et al., 1997). Ainda no grupo de ligação N, a 3,2 cM do marcador Satt009, foi mapeado um loco de resistência a Phytophthora sojae - patógeno causador da podridão-radicular em soja e ligado ao marcador Satt080 -, e um QTL de resistência a Fusarium solani f. sp. glycines, causador da podridão-vermelha-da-raiz, também conhecida com síndrome da morte súbita da soja (Njiti et al., 2002).

Outros marcadores moleculares ligados a várias doenças da soja já foram relatados na literatura. Funganti et al. (2004) identificaram o marcador

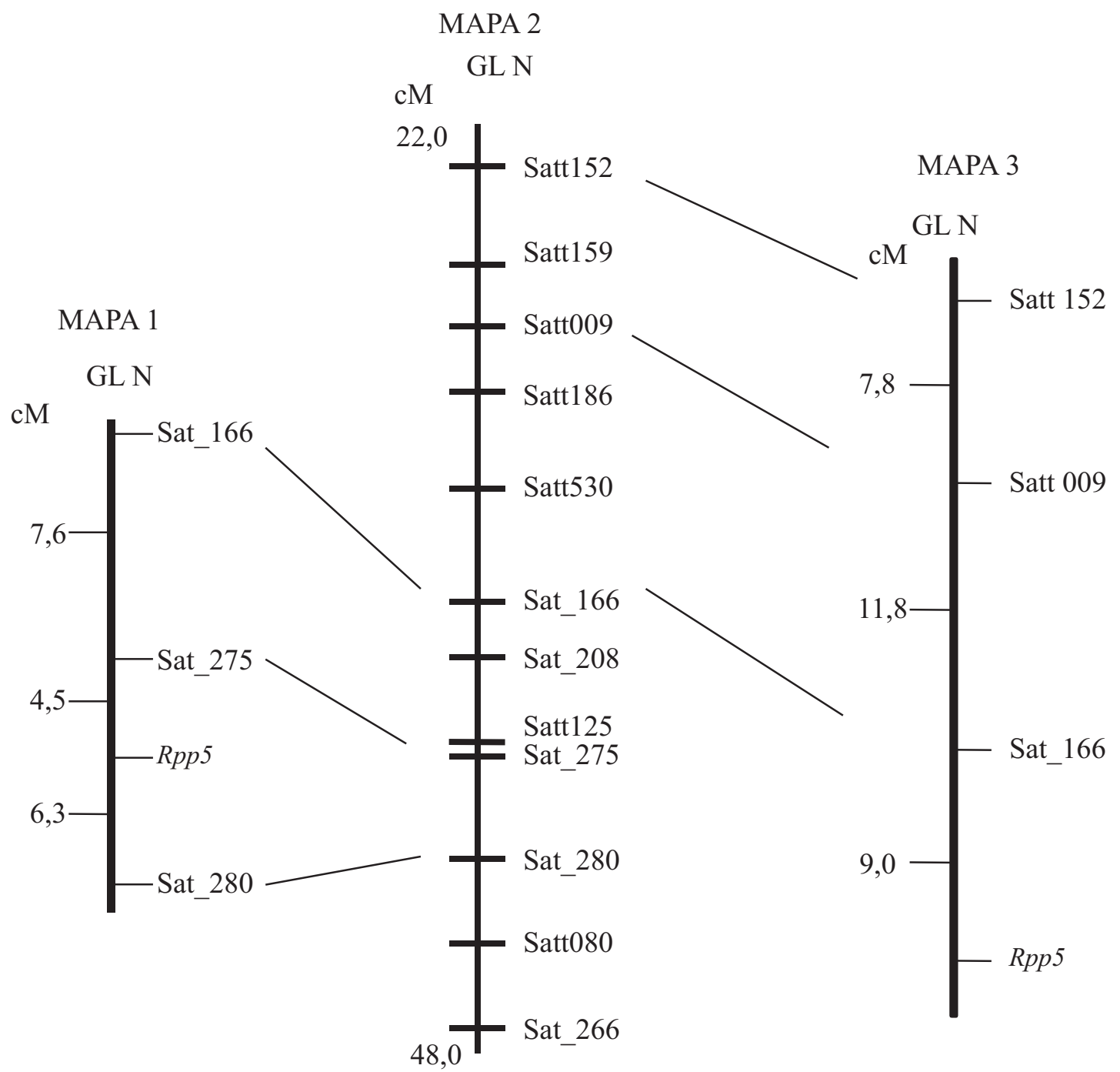

Figura 1. Mapa de ligação com indicação do posicionamento do gene de resistência à ferrugem-asiáticada-soja (Rpp5), em relação aos marcadores microssatélites polimórficos. Mapa 1: mapa genético descrito por Garcia et al. (2007); mapa 2: parte do grupo de ligação consenso N, com indicação dos marcadores mapeados na região. A porção do mapa de ligação consenso foi gerada na página "web" da Soybase (mapa físico da cultivar Williams (http://soybase.agron.iastate.edu/resources/ssr.php); mapa 3: mapa genético gerado no presente estudo. 
Satt114 ligado ao loco de resistência ao nematóideda-galha, no grupo de ligação F. O marcador Satt215 mostrou-se ligado ao gene $R b s 1$, que confere resistência à podridão-parda-da-haste, com eficiência de seleção de $88 \%$ (Bachman et al., 2001). Um novo gene, $\operatorname{Rcs}_{\text {Peking, }}$ que confere resistência à mancha-olho-de-rã, foi mapeado a 1,1 cM do marcador Satt244, no grupo de ligação G (Yang et al., 2001).

A busca por marcadores moleculares, ligados à resistência às doenças, e sua utilização na seleção assistida por marcadores moleculares (SAM) para o desenvolvimento de cultivares resistentes, é uma realidade em diversos programas de melhoramento. A SAM é considerada um avanço da genética molecular e veio somar-se a outros procedimentos, utilizados para facilitar o processo de melhoramento.

Assim, foi determinada a eficiência de seleção de cada marcador, identificado como ligado ao gene Rpp5 de resistência à ferrugem-asiática-da-soja, para a utilização na SAM em programas de melhoramento, com finalidade resistência ao patógeno $P$. pachyrhizi, quando a mesma fonte de resistência for utilizada.

Para Satt152, Satt009, Sat166, Sat_280 e Sat_275 isoladamente, as eficiências de seleção foram de $56,36,68,52,82,98,89,36$ e $97,56 \%$, respectivamente (Tabela 3). A maior eficiência individual de seleção obtida foi com a utilização do marcador Sat 275 (97,56\%), mapeada a $4,5 \mathrm{cM}$ do gene de resistência por Garcia et al. (2008).

A utilização da combinação dos marcadores Sat_275 + Sat_280, que flanqueiam o gene de resistência, resultou na maior e total eficiência de seleção (100\%). Portanto, a utilização desses marcadores para a seleção assistida é válida, pois identifica os genótipos homozigóticos e o gene de resistência pode ser fixado em poucos ciclos de seleção.

Tabela 3. Eficiência de seleção dos marcadores ligados ao gene Rpp 5 de resistência à ferrugem-asiática-da-soja.

\begin{tabular}{lcc}
\hline Marcadores & $\begin{array}{c}\text { Plantas resistentes } \\
\text { selecionadas }\end{array}$ & $\begin{array}{c}\text { Eficiência } \\
\text { de seleção (\%) }\end{array}$ \\
\hline Satt152 & 17 & 56,36 \\
Satt009 & 19 & 68,52 \\
Sat_166 & 19 & 82,98 \\
Sat_275 & 22 & 97,56 \\
Sat_280 & 20 & 89,36 \\
Sat_275+Sat_280 & 20 & 100,00 \\
\hline
\end{tabular}

\section{Conclusões}

1. Os marcadores SSR Satt009 e Satt152 apresentamse ligados ao gene Rpp5 de resistência à ferrugemasiática-da-soja, no grupo de ligação N.

2. A combinação Sat275 + Sat280 apresenta eficiência total $(100 \%)$, na seleção de plantas com resistência à ferrugem-asiática-da-soja.

3. Os marcadores ligados ao gene Rpp5 são úteis, na seleção assistida para a ferrugem-asiática-da-soja, em estágios iniciais do desenvolvimento das plantas e sem a exposição ao patógeno.

\section{Agradecimentos}

À Coordenação de Aperfeiçoamento de Pessoal de Nível Superior, pela concessão de bolsas; à Dra. Lucimara Chiari, pelas críticas e sugestões ao trabalho.

\section{Referências}

ALVES, S.A.M. Quantificação de parâmetros da pré-penetração e monocíclicos relacionados ao patossistema Phakopsora pachyrhizi-soja. 2007. 64p. Tese (Doutorado) - Escola Superior de Agricultura Luiz de Queiroz, Piracicaba.

ARAHANA, V.S.; GRAEF, G.L.; SPECHT, J.E.; STEADMAN, J.R.; ESKRIDGE, K.M. Identification of QTLs for resistance of Sclerotinia sclerotiorum in soybean. Crop Science, v.41, p.180-188, 2001.

AZALTE-MARIN, A.L.; CERVIGNI, G.D.L.; MOREIRA, M.A.; BARROS, E.G. Seleção assistida por marcadores moleculares visando ao desenvolvimento de plantas resistentes a doenças, com ênfase em feijoeiro e soja. Fitopatologia Brasileira, v.30, p.333-342, 2005.

BACHMAN, M.S.; TAMULONIS, J.P.; NICKELL, C.D.; BENT, A.F. Molecular markers linked to brown stem rot resistance genes, $R b s 1$ and $R b s 2$, in soybean. Crop Science, v.41, p.527-535, 2001.

BROMFIELD, K.R.; HARTWIG, E.E. Resistance to soybean rust and mode of inheritance. Crop Science, v.20, p.254-255, 1980.

CONAB. Companhia Nacional de Abastecimento. Acompanhamento da safra brasileira: grãos: sexto levantamento, março 2008. Brasília, DF, 2008. 30p.

CONCIBIDO, V.C.; LANGE, D.A.; DENNY, R.L.; ORF, J.H.; YOUNG, N.D. Genome mapping of soybean cyst nematode resistance genes in "Peking", PI 90763, and PI 88788 using DNA markers. Crop Science, v.37, p.258-264, 1997.

CRUZ, C.D.; SCHUSTER, I. GQMOL: aplicativo computacional para análise de dados moleculares e de suas associações com caracteres quantitativos. Versão 9.1. 2006. Disponível em: $<$ http:// www.ufv.br/dbg/gqmol/gqmol.htm>. Acesso em: 1ํ dez. 2007. 
FEHR, W.R.; CAVINESS, J.A. Stages of soybean development. Aimes: Iowa State University, 1977. 11p. (Special Report, 80).

FERREIRA, M.E.; GRATTAPAGLIA, D. Introdução ao uso de marcadores moleculares em análise genética. 3 ed. Brasília: Embrapa-Cenargen, 1998. 220p.

FUNGANTI, R.; BENEVENTI, M.A.; SILVA, J.F.V.; ARRIAS, C.A.A.; MARIN, S.R.R.; BINNEK, E.; NEPOMUCENO, A.L. Identificação de marcadores moleculares de microssatélites para a seleção de genótipos de soja resistentes a Meloidogyne javanica. Nematologia Brasileira, v.28, p.125-130, 2004.

GARCIA, A.; CALVO, E.S.; KIIHL, R.A.S.; HARADA, A.; HIROMOTO, D.M.; VIEIRA, L.G. Molecular mapping of soybean rust (Phakopsora pachyrhizi) resistance genes: discovery of a novel locus and alleles. Theoretical and Applied Genetics, v.117, p. $545-553,2008$.

GODOY C.V.; CANTERI, M.G. Efeitos protetor, curativo e erradicante de fungicidas no controle da ferrugem-da-soja causada por Phakopsora pachyrhizi, em casa de vegetação. Fitopatologia Brasileira, v.29, p.97-101, 2004.

GORDON, S.G.; MARTIN, S.K.S.; DORRANCE, A.E. Rps 8 maps to a resistance gene rich on soybean molecular linkage group F. Crop Science, v.46, p.168-173, 2006.

HARTWIG, E.E. Identification of fourth major gene conferring resistance to soybean rust. Crop Science, v.26, p.1135-1136, 1986.

HARTWIG, E.E.; BROMFIELD, K.R. Relationships among three genes conferring specific resistance to rust in soybeans. Crop Science, v.23, p.237-239, 1983.

HYTEN, D.L.; HARTMAN, G.L.; NELSON, R.L.; FREDERICK, R.D.; CONCIBIDO, V.C.; NARVEL, J.M.; CREGAN, P.B. Map location of the Rppl locus that confers resistance to soybean rust in soybean. Crop Science, v.47, p.837-838, 2007.

KOSAMBI, D.D. The estimation of map distance from recombination values. Annals of Eugenics, v.12, p.172-175, 1944.

MARTINS, J.A.S. Caracteres epidemiológicos e uso da análise de agrupamento para a resistência parcial à ferrugem-da-soja. 2006. 53p. Dissertação (Mestrado) - Universidade Federal de Uberlândia, Uberlândia.

MCLEAN, R.J.; BYTH, D.E. Inheritance of resistance to rust (Phakopsora pachyrizi) in soybeans. Australian Journal of Agricultural Research, v.31, p.951-956, 1980.

MICHELMORE, R.W.; PARAN, I.; KESSELI, R.V. Identification of markers linked to disease resistance genes by bulked segregant analysis: a rapid method to detect markers in specific genomic regions by using segregation populations. Proceedings of the National Academy Science USA, v.88, p.9828-9832, 1991.

MIAN, M.A.R.; WANG, T.Y.; PHILLIPS, D.V.; ALVERNAZ, J.; BOERMAN, H.R. Molecular mapping of the Rcs3 gene for resistance to frogeye leaf spot in soybean. Crop Science, v.39, p.1687-1691, 1999.

NJITI, V.N.; MEKSEM, M.; IQBAL, J.; JOHNSON, J.E.; KASSEM, M.A.; ZOBRIST, F.; KILO, V.Y.; LIGHTFOOT, D.A. Common loci underlie fiels resistance to soybean sudden death syndrome in Forrest, Pyramid, Essex, and Douglas. Theoretical and Applied Genetics, v.104, p.294-300, 2002.

SILVA, D.C.G.; YAMANAKA, N.; BROGIN, R.L.; ARIAS, C.A.A.; NEPOMUCENO, A.L.; DI MAURO, A.O.; PEREIRA, S.S.; NOGUEIRA, L.M.; PASSIANOTO, A.L.L.; ABDELNOOR, R.V. Molecular mapping of two loci that confer resistance to Asian rust in soybean. Theoretical and Applied Genetics, v.117, p.57-63, 2008.

SILVA, M.F.; SCHUSTER, I.; SILVA, J.F.V.; FERREIRA, A.; BARROS, E.G.; MOREIRA, M.A. Validation of microssatellite markers for assisted selection of soybean resistance to cyst nematode races 3 and 14. Pesquisa Agropecuária Brasileira, v.42, p.1143-1150, 2007.

SOARES, R.M.; RUBIN, S.A.L.; WIELEWICKI, A.P.; OZELAME, J.G. Fungicidas no controle da ferrugem-asiática (Phakopsora pachyrhizi) e produtividade da soja. Ciência Rural, v.34, p.1245-1247, 2004.

SONG, Q.J.; MAREK, L.F.; SHOEMAKER, R.C.; LARK, K.G.; CONCIBIDO, V.C.; DELANNAY, X.; SPECHT, J.E.; CREGAN, P.B. A new integrated genetic linkage map of the soybean. Theoretical and Applied Genetics, v.109, p.122-128, 2004.

WENG, C.; YU, K.; ANDERSON, T.R.; POYSA, V. Mapping genes conferring resistance to Phytophthora root rot of soybean, Rps 1 a and Rps7. The Journal of Heredity, v.92, p.442-446, 2001.

YANG, W.; WEAVER, D.B.; NIELSEN, B.L.; QIU, J. Molecular mapping of a new gene for resistance to frogeye leaf spot in soybean in "Peking". Plant Breeding, v.120, p.73-78, 2001.

ZAMBENEDETTI, E.B.; ALVES, E.; POZZA, E.A.; ARAÚJO, D.V.; GODOY, C.V. Avaliação de parâmetros monocíclicos e da intensidade da ferrugem-asiática (Phakopsora pachyrhizi) em diferentes genótipos de soja e posições de copa. Summa Phytopathologica, v.33, p.178-181, 2007.

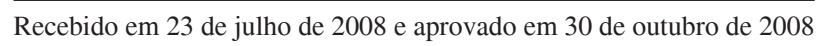


